\title{
A social work study on the effect of training program for parents of children with attention deficit/ hyperactivity disorder
}

\author{
Ladan Azarnoush $^{\mathrm{a}^{*}}$, Yousef Gorji ${ }^{\mathrm{b}}$ and Afsaneh Javadzade
}

${ }^{a}$ MS Student, Counseling Department, Islamic Azad University of Khomeinishahr, Khomeinishahr Branch, Daneshjou Blvd, Iran

${ }^{b}$ Assistant Professor, Counseling Department, Islamic Azad University of Khomeinishahr, Khomeinishahr Branch, Daneshjou Blvd, Iran

${ }^{c}$ Assistant Professor, Counseling Department, Islamic Azad University of Khomeinishahr, Khomeinishahr Branch, Daneshjou Blvd, Iran

\section{H R O N I C L E}

Article history:

Received May 18, 2013

Received in revised format

12 August 2013

Accepted 5 September 2013

Available online

September 72013

Keywords:

ADHD

Marital satisfaction

Children with attention deficit/

hyperactivity disorder

\section{Introduction}

Attention-Deficit/Hyperactivity Disorder (ADHD) is one of issues among children in any society and some studies indicate that there are some associated between ADHD and family characteristics (Campbell, 2000; Schaefer \& Briesmeister, 1989; Whalen \& Henker, 1988; Biederman et al., 1991; Sprafkin \& Carlson, 1992; Barkley, 2000). ADHD is considered as the most common childhood psychiatric disorder and probably one of the most common undiagnosed psychiatric disorders among most adults. ADHD normally begins in childhood and may be followed by a lifelong expression of symptoms, including inattention, excessive motor hyperactivity or restlessness, and poor impulse control. Standard measures exist for evaluating the disorder and evaluating treatment influences

*Corresponding author. Tel: +989133053913

E-mail address: ladan.azarnoush@iaukhsh.ac.ir (L. Azarnous)

C) 2013 Growing Science Ltd. All rights reserved.

doi: $10.5267 /$ j.ms 1.2013 .09 .006 
(Schweitzer et al., 2001). There are different medications for ADHD. May and Kratochvil (2010), for instance, considered the efficacy and safety of five of the more novel long-acting pharmacological treatments approved by the FDA for marketing in the US for paediatric ADHD, along with an $\alpha 2$ adrenoceptor agonist in preparation.

Johnston and Mash (2001), for instance, reported that the presence of ADHD in children was associated to varying degrees with disturbances in family and marital functioning, disrupted parentchild relationships, specific patterns of parental cognitions about child behavior and reduced parenting self-efficacy, and increased levels of parenting stress and parental psychopathology, particularly when ADHD is comorbid with conduct problems. August (1987) compared free recall of weakly categorizable words in hyperactive $(\mathrm{ADDH})$, reading-disabled, and normal boys and reported that hyperactive boys recalled fewer words than did the reading-disabled and normal boys, despite maintaining equality in category organization.

Barkley (1988) investigated the effects of two doses of methylphenidate on the interactions of 27 ADHD children with their mothers were assessed using a double-blind, placebo-controlled crossover design. They reported few drug effects during free play at either dose of medication, except for a decrease in the mothers' implementation of commands during the low dose of medication. Attention deficit hyperactivity disordered children on high doses reduced their off-task and noncompliant behavior and substantially increased their rates of compliance as well as the length of sustained compliance with maternal commands.

Taniguchi et al. (2006) performed an investigation of married couples' perceptions of marital satisfaction in outdoor recreation. Schumacher and Leonard (2005) investigated husbands' and wives' marital adjustment, verbal aggression, and physical aggression as longitudinal predictors of physical aggression in early marriage. Twenge et al. (2003) performed a comprehensive review on parenthood and marital satisfaction. They reported the effect of parenthood on marital satisfaction was more negative among high socioeconomic groups, younger birth cohorts, and in more recent years. The data recommended that marital satisfaction decreased after the birth of a child due to role conflicts and restriction of freedom.

Medication in the United States is often considered as the first intervention to medicate ADHD. However, there are other alternative treatments such as psychological interventions with both parents and teachers working together to shape the child's attitude. McGuinness (2008) provided key nursing interventions on behalf of children with ADHD, which includes evaluating parental knowledge about treatment, listening supportively to parents and promoting partnership among parents and teachers.

\section{The method}

In this paper, we study the effect of training on parents' behavior on children with ADHD. The main hypothesis of this paper studies whether parental training influences on marital satisfaction among parents having to children with ADHD or not. The population of this survey includes all parents having children ages 5-12 year with ADHD who approached medical centers during the first three months of fiscal year of 2011 in city of Esfahan, Iran.

The study designs a questionnaire, which includes 12 marriage characteristics with 47 questions including A contract (distorted dream), marital satisfaction, personality issues, marital communication, conflict resolution, financial monitoring (financial management), leisure activities, marital relationships, marriage, children, relatives and friends, the related to gender equality (egalitarianism) and the orientation of conscience (Religious). The study has selected a random sample of 30 couples and divided them into two equal groups with 15 people where half were considered as experiment and the other half were considered as control. Cronbach alpha has been calculated as 0.92 , which is well above the minimum acceptable level. Fig. 1 demonstrates personal characteristics of the participants. 


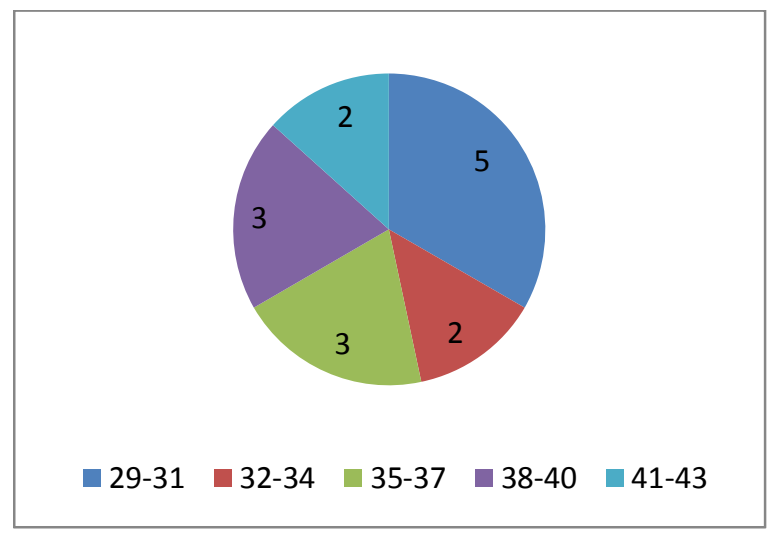

Frequency of Age (Both group)

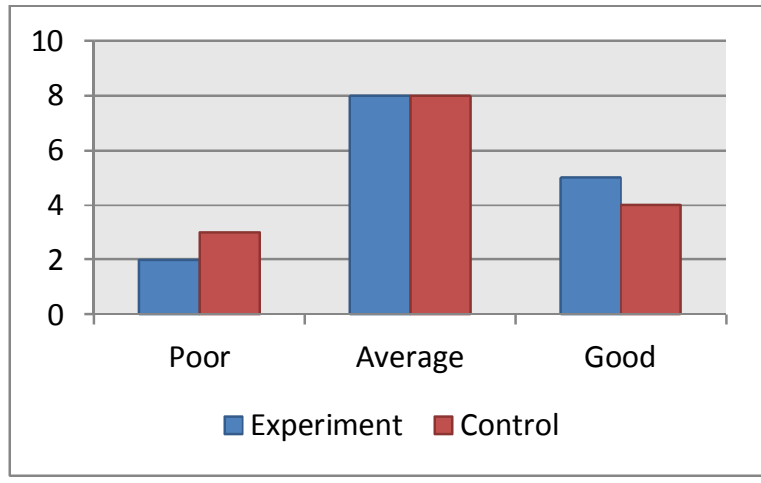

Economic conditions

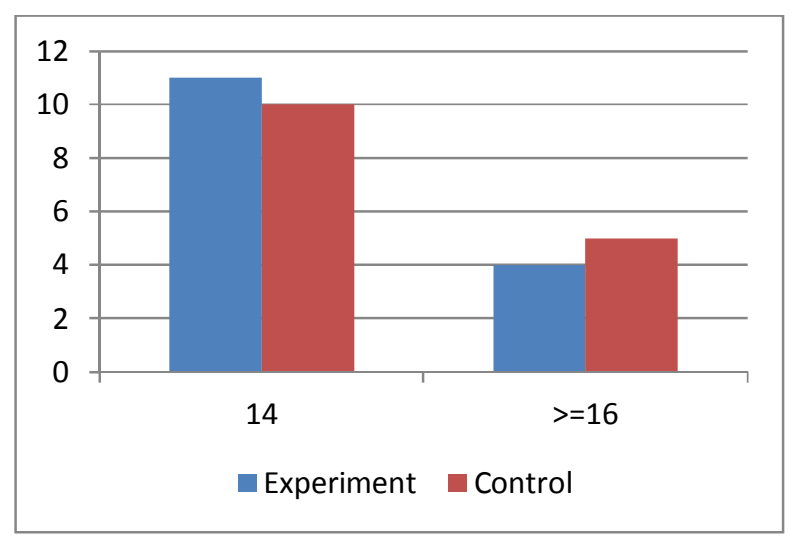

Years of education

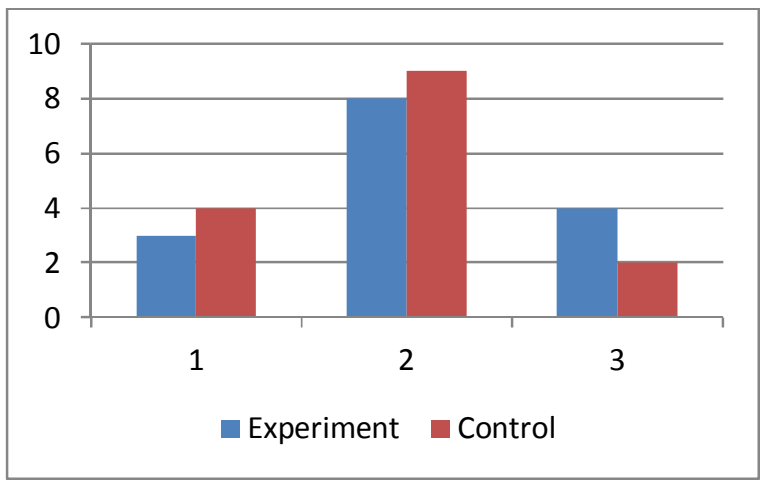

Number of children

Fig. 1. Personal characteristics of the participants

As we can observe from the results of Fig. 1, participants in our survey are mostly middle age people and they are highly educated. In terms of income, they consider themselves as middle class people and most of them have two children.

\section{The results}

In this section, we present details of scores given to marital satisfaction in each group in terms of mean and standard deviation.

Table 1

The summary of mean and standard deviation of scores given to experiment and control groups

\begin{tabular}{llccc}
\hline \multirow{2}{*}{ Group } & \multirow{2}{*}{ Attribute } & Pre-test & Post-test & Follow up \\
\hline \multirow{2}{*}{ Experiment } & Mean & 27.88 & 24.98 & 25.44 \\
& Standard deviation & 1.14 & 1.14 & 1.13 \\
\hline \multirow{2}{*}{ Control } & Mean & 28.94 & 25.63 & 25.61 \\
& Standard deviation & 1.09 & 1.10 & 1.09 \\
\hline \multirow{2}{*}{ Total } & Mean & 27.97 & 24.94 & 25.15 \\
& Standard deviation & 1.12 & 1.12 & 1.11 \\
\hline
\end{tabular}


According to the results of Table 1, the average number for experiment and control groups have been reduced from 27.88 and 28.94 to 24.98 and 25.63 , respectively when the test has been accomplished. Before we go further, we need to make sure that the data are normally distributed. This has been accomplished using Kolmogorov-Smirnov test (Stuart et al., 1970; Justel et al., 1997; Eadie et al., 1971), which are summarized in Table 2 as follows,

Table 2

The summary of One-Sample Kolmogorov-Smirnov Test

\begin{tabular}{ccc}
\hline \multirow{2}{*}{ Group } & Attribute & Variable \\
& & Marital satisfaction \\
\hline \multirow{2}{*}{ Experiment } & Statistics & 0.876 \\
& Sig. & 0.052 \\
\hline \multirow{2}{*}{ Control } & Statistics & 0.932 \\
& Sig. & 0.29 \\
\hline
\end{tabular}

The results of Table 2 specify that all data are normally distributed when the level of significance is five percent. In addition, Levin test for comparing the variances of two samples yields the following,

Table 3

The summary of Levin test

\begin{tabular}{ccccc}
\hline Stage & F-value & Degree of freedom 1 & Degree of freedom 2 & Sig. \\
\hline Pre-test & 0.024 & 1 & 28 & 0.877 \\
\hline
\end{tabular}

As we can observe from the result of Table 3, Levin test is not meaningful when the level of significance is five percent. Nevertheless, the pre-assumption of equality of variances are approved using Macheli test (Mauchly, 1940; Maxwell \& Delaney, 1990), we perform Greenhouse-Geisser test (Greenhouse \& Geisser, 1959; Howell, 2009; O'Brien \& Kaiser, 1985) to analyze the variances for three groups of pre-test, post-test and follow up for two groups of control and experiment, and Table 4 shows details of our survey.

\section{Table 4}

The summary of Greenhouse-Geisser test

\begin{tabular}{lccccccc}
\hline $\begin{array}{l}\text { Source of } \\
\text { changes }\end{array}$ & $\begin{array}{l}\text { Sum of } \\
\text { squares }\end{array}$ & $\mathrm{df}$ & $\begin{array}{c}\text { Mean of } \\
\text { squares }\end{array}$ & $\mathrm{F}$ & Sig. & $\begin{array}{c}\text { Volume } \\
\text { of }\end{array}$ & $\begin{array}{c}\text { Power of } \\
\text { statistics }\end{array}$ \\
\hline Different groups & 1.861 & 1.966 & 0.946 & 0.095 & 0.907 & 0.003 & 0.064 \\
\hline
\end{tabular}

The result of Greenhouse-Geisser test clearly specifies that there is not a meaningful difference between two groups before/after the exam. Therefore, we can conclude that applying training program did not have any meaningful effect on parents of children with attention deficit/ hyperactivity disorder.

\section{Conclusion}

In this paper, we have performed an empirical investigation on some selected people to examine the effects of training programs on marital satisfaction among parents with children having ADHD. There seems that applying standard training program did not have any influential effect in our survey on their marital satisfaction. In other words, training program could not improve quality of marital satisfaction in terms of different components such as personality issues, marital communication, conflict resolution, financial monitoring, etc. 


\section{Acknowledgement}

The authors would like to thank consoling center of city of Esfahan for cordially cooperating in accomplishment of this survey.

\section{References}

August, G. J. (1987). Production deficiencies in free recall: A comparison of hyperactive, learningdisabled, and normal children. Journal of Abnormal Child Psychology, 15(3), 429-440.

Barkley, R. A. (1988). The effects of methylphenidate on the interactions of preschool ADHD children with their mothers. Journal of the American Academy of Child \& Adolescent Psychiatry, 27(3), 336-341.

Barkley, R.A. (2000). Taking charge of ADHD. New York: The Guilford Press.

Biederman, J., Newcorn, J., \& Sprich, S. (1991). Comorbidity of Attention Deficit Hyperactivity Disorder. American Journal of Psychiatry, 148(5).

Campbell, S. B. (2000). Attention-deficit/hyperactivity disorder. In Handbook of developmental psychopathology (pp. 383-401). Springer US.

Eadie, W.T., Drijard, D., James, F.E., Roos, M., \& Sadoulet, B. (1971). Statistical Methods in Experimental Physics. Amsterdam: North-Holland, 269-271.

Greenhouse, S.W., \& Geisser, S. (1959). On methods in the analysis of profile data. Psychometrika, 24, 95-112.

Howell, D.C. (2009). Statistical Methods for Psychology. Wadsworth Publishing.

Johnston, C., \& Mash, E. J. (2001). Families of children with attention-deficit/hyperactivity disorder: review and recommendations for future research. Clinical Child and Family Psychology Review, 4(3), 183-207.

Justel, A., Peña, D., \& Zamar, R. (1997). A multivariate Kolmogorov-Smirnov test of goodness of fit. Statistics \& Probability Letters, 35(3), 251-259.

May, D. E., \& Kratochvil, C. J. (2010). Attention-Deficit Hyperactivity Disorder. Drugs, 70(1), 1540.

Maxwell, S.E. \& Delaney, H.D. (1990). Designing experiments and analyzing data: A model comparison perspective. Belmont: Wadsworth.

McGuinness, T. M. (2008). Helping parents decide on ADHD treatment for their children. Journal of Psychosocial Nursing and Mental Health Services, 46(8), 23-27.

Miller, K. J., \& Castellanos, F. X. (1998). Attention deficit/hyperactivity disorders. Pediatrics in review, 19(11), 373-384.

Mauchly, J.W. (1940). Significance test for sphericity of a normal n-variate distribution. The Annals of Mathematical Statistics, 11, 204-209.

O'Brien, R.G. \& Kaiser, M.K. (1985). The MANOVA approach for analyzing repeated measures designs: An extensive primer. Psychological Bulletin, 97, 316-333.

Schaefer, C. E., \& Briesmeister, J. M. (1989). Handbook of parent training: Parents as co-therapists for children's behavior problems. John Wiley \& Sons.

Schumacher, J. A., \& Leonard, K. E. (2005). Husbands' and wives' marital adjustment, verbal aggression, and physical aggression as longitudinal predictors of physical aggression in early marriage. Journal of Consulting and Clinical Psychology, 73(1), 28.

Sprafkin, J., \& Carlson, G. A. (1992). Attention-Deficit Hyperactivity Disorder: A handbook for diagnosis and treatment. American Journal of Psychiatry, 149(9), 1266-1266.

Schweitzer, J. B., Cummins, T. K., \& Kant, C. A. (2001). Attention-deficit/hyperactivity disorder. Medical Clinics of North America, 85(3), 757-777.

Stuart, A., Ord, K., Arnold, S. F. (1999). Classical Inference and the Linear Model. Kendall's Advanced Theory of Statistics 2A, $6^{\text {th }}$ ed. London: Arnold. 25.37-25.43. 
Taniguchi, S. T., Freeman, P. A., Taylor, S., \& Malcarne, B. (2006). A study of married couples' perceptions of marital satisfaction in outdoor recreation. Journal of Experiential Education, 28(3), 253-256.

Twenge, J. M., Campbell, W. K., \& Foster, C. A. (2003). Parenthood and marital satisfaction: A meta-analytic review. Journal of Marriage and Family, 65(3), 574-583.

Whalen, C. K., \& Henker, B. (1998). Attention-deficit/hyperactivity disorders. Handbook of child psychopathology, 3, 181-211. 